\title{
Managed clinical protocol: impact of implementation on sepsis treatment quality indicators
}

\author{
Protocolo clínico gerenciado: impacto da implementação nos indicadores de qualidade do tratamento da sepse
}

Protocolo clínico gestionado: impacto de la implementación en los indicadores de calidad del tratamiento de la sepsis

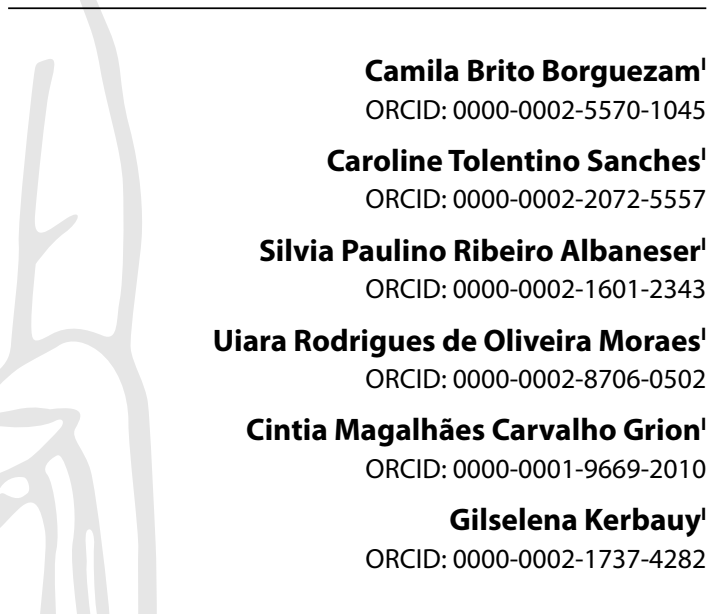

'Universidade Estadual de Londrina. Londrina, Paraná, Brazil.

How to cite this article: Borguezam CB, Sanches CT, Albaneser SPR, Moraes URO, Grion CMC, Kerbauy G. Managed clinical protocol: impact of implementation on sepsis treatment quality indicators.

Rev Bras Enferm. 2021;74(2):e20200282

https://doi.org/10.1590/0034-7167-2020-0282

Corresponding author:

Gilselena Kerbauy

E-mail: gilselena@hotmail.com

EDITOR IN CHIEF: Antonio José de Almeida Filho ASSOCIATE EDITOR: Álvaro Sousa

Submission: 06-06-2020

Approval: 11-12-2020

\begin{abstract}
Objectives: to assess the impact of the implementation of a managed sepsis protocol on quality indicators of treatment for septic patients in an emergency department of a university hospital. Methods: an observational epidemiological study involving septic patients. The study was divided into two phases, pre-intervention and intervention, resulting from the implementation of the managed sepsis protocol. The study variables included sepsis treatment quality indicators. The results were statistically analyzed using the program Epi Info ${ }^{\mathrm{TM}}$. Results: the study sample included 631 patients, 95 from pre-intervention phase and 536 from intervention phases. Implementing the protocol increased patients' chances of receiving the recommended treatment by 14 times. Implementing the protocol reduced the hospitalization period by 6 days $(p<0.001)$ and decreased mortality $(p<0.001)$. Conclusions: this study showed that implementing the managed protocol had an impact on the improvement of sepsis treatment quality indicators.

Descriptors: Clinical Protocols; Sepsis; Nursing; Quality Indicators, Health Care; Emergency Treatment.
\end{abstract}

\section{RESUMO}

Objetivos: avaliar o impacto da implementação de protocolo clínico gerenciado de sepse nos indicadores de qualidade do tratamento de pacientes sépticos atendidos em setor de urgência e emergência de um hospital universitário. Métodos: estudo epidemiológico observacional envolvendo pacientes sépticos. O estudo se dividiu em duas fases, préintervenção e intervenção, decorrente da implementação do protocolo gerenciado de sepse. As variáveis do estudo contemplaram os indicadores de qualidade do tratamento da sepse. Os resultados foram analisados estatisticamente pelo programa Epi Info ${ }^{\mathrm{TM}}$. Resultados: a amostra do estudo contemplou 631 pacientes, 95 da fase pré-intervenção e 536 da fase intervenção. A implementação do protocolo aumentou em 14 vezes as chances de o paciente receber o tratamento recomendado. A implementação do protocolo reduziu em 6 dias o período de hospitalização $(p<0,001)$ e diminuiu a mortalidade $(p<0,001)$. Conclusões: $o$ estudo evidenciou que a implementação do protocolo gerenciado impactou na melhoria dos indicadores de qualidade no tratamento da sepse.

Descritores: Protocolos Clínicos; Sepse; Enfermagem; Indicadores Básicos de Saúde; Tratamento de Emergência.

\section{RESUMEN}

Objetivos: evaluar el impacto de la implementación de un protocolo de sepsis manejada sobre los indicadores de calidad del tratamiento del paciente séptico en el servicio de urgencia de un hospital universitario. Métodos: estudio epidemiológico observacional con pacientes sépticos. El estudio se dividió en dos fases, preintervención e intervención, resultado de la implementación del protocolo de sepsis manejada. Las variables de estudio incluyeron indicadores de calidad del tratamiento de la sepsis. Los resultados fueron analizados estadísticamente por el programa Epi Info ${ }^{T M}$. Resultados: la muestra de estudio incluyó a 631 pacientes, 95 de la fase de preintervención y 536 de la fase de intervención. La implementación del protocolo aumentó 14 veces las posibilidades de que el paciente recibiera el tratamiento recomendado. La implementación del protocolo redujo el período de hospitalización en 6 días $(p<0,001)$ y disminuyó la mortalidad $(p<0,001)$. Conclusiones: el estudio mostró que la implementación del protocolo gestionado incidió en la mejora de los indicadores de calidad en el tratamiento de la sepsis.

Descriptores: Protocolos Clínicos; Sepsis; Enfermería; Indicadores de Salud; Tratamiento de Urgencia. 


\section{INTRODUCTION}

Sepsis is defined as a potentially fatal organ dysfunction caused by an unregulated organic response resulting from an infectious process. In some cases, it can evolve to circulatory and metabolic changes, classified as septic shock ${ }^{(1)}$.

Sepsis is estimated to reach 31.5 million people a year ${ }^{(2)}$. In a study of global sepsis incidence and mortality, 11 million deaths were related to sepsis, accounting for $19.7 \%$ of all global deaths in $2017^{(3)}$.

An important Brazilian study that evaluated the prevalence of sepsis in Intensive Care Units (ICU) in a pseudo-random sample, nationally representative, showed that the density of sepsis incidence was 36.3 per 1000 patient/days and mortality reached $55.7 \%$ of cases. The projected sepsis incidence rate was 290 adult cases of sepsis treated in ICU per year per 100,000 inhabitants, totaling about 420,000 cases per year and 230,000 deaths in $2014^{(4)}$.

In addition to the high impact on mortality, sepsis is considered one of the main causes of rising costs for healthcare institutions, and in 2013 it totaled an expenditure of approximately 24 billion dollars in the United States ${ }^{(5)}$ and an average of $\mathrm{R} \$ 38,867.60$ (reais is the Brazilian currency) in costs per septic patient in a Brazilian public hospital $^{(6)}$.

Faced with alarming epidemiological data, American and European intensive care societies formally acknowledged the seriousness of the problem and launched in 2004 the worldwide campaign called Surviving Sepsis Campaign (SSC), aiming at reducing sepsis mortality worldwide ${ }^{(7-8)}$.

SSC recommendations impacted mortality decrease worldwide, especially in Australia and New Zealand, in a retrospective study that addressed septic patients diagnosed and treated between 2000 and 2012, when deaths from sepsis went from $35 \%$ to $18.4 \%$ as a result of early recognition and antimicrobial administration $^{(9)}$.

Within the emergency sector, a multicenter study showed that there is a need for systematic improvement in the initial treatment of inpatients with sepsis in these sectors, focusing on early recognition and comprehensive patient approach ${ }^{(10)}$. Among the strategies, implementing managed protocols stands out, a strategy that aligns the best evidence in sepsis treatment with actions organized in health services for recognition and treatment, staff training, composition of professional staff to support actions, as well as measurement of indicators to assess results ${ }^{(11)}$.

Considering the global relevance of the theme and the need to implement measures to support sepsis recognition and treatment, especially in emergency services, and the scarcity of national studies that report the implementation of managed sepsis protocols, as well as its impact on treatment indicators, it is necessary to conduct research in this context.

\section{OBJECTIVES}

To assess the impact of implementing a managed sepsis protocol on quality indicators of treatment for septic patients in an emergency department of a university hospital.

\section{METHODS}

\section{Ethical aspects}

This study was linked to the project "Adequação e Implantação de um protocolo Assistencial Gerenciado de Tratamento de Pacientes com Sepse em um Hospital Universitário", authorized by the institution of the study and approved by the Research Ethics Committee involving Human Beings of Universidade Estadual de Londrina. The research data were collected from secondary sources, and the project was approved with the waiver of the Informed Consent Form.

\section{Study design, period, and location}

This is an observational epidemiological study guided by STROBE (STrengthening the Reporting of OBservational studies in Epidemiology), which aimed to assess the impact of implementing the sepsis managed care clinical protocol on quality indicators of care for sepsis treatment in an emergency department of a university hospital, from December 2013 to March 2018.

The study hospital is a reference in high complexity for the Unified Health System (SUS - Sistema Único de Saúde), composed of 343 beds distributed among inpatient units, emergency room and ICU.

The emergency sector has three emergency rooms in addition to 48 observation beds and assists an average of 75 patients per day, with an average occupancy above its maximum capacity. It has an emergency laboratory that operates 24 hours a day in carrying out emergency tests and a satellite pharmacy.

\section{Managed Sepsis Protocol}

At the initiative of nursing and medical departments linked to Universidade Estadual de Londrina and with support of the clinical director and superintendent of the University Hospital, in 2013, a care protocol was conceived, planned and implemented to care for patients diagnosed with sepsis in the emergency sector. This care protocol was institutionally implemented in the health service by the institution's clinical and nursing management.

The protocol implementation, assessed in the present study, took place in two phases: the first phase, called pre-intervention, started 6 months before the protocol implementation (December/2013 to May/2014); in this stage, clinical data collection and patient care and treatment were performed.

The second phase, called intervention (June/2014 to March/2018), consisted of implementing the managed sepsis protocol, following recommendations from SSC and the Latin American Sepsis Institute (ILAS - Instituto Latino-Americano de Sepse).

Throughout this phase, training was provided for multidisciplinary health staff in the emergency sector, composed of physicians, nursing technicians, nurses, pharmacists, laboratory technicians and exam collectors, as well as residents and interns of nursing and medical courses. Trainings took place on-sight, in the study sector, during the time of permanence of sector professionals, and were offered monthly according to the exchange of residents and interns of medical and nursing courses. They were taught by protocol nurse managers, and addressed 
the pathophysiology, clinical signs, diagnosis and treatment of sepsis, as well as the guidelines for using the checklist.

A patient care flowchart was defined and printed forms, called Kit Sepse, were made available in the sector. They contained checklist forms with steps for recognition, diagnosis and treatment of sepsis, as well as forms for requesting antimicrobial laboratory tests and quick release. Filling out such forms was directed to nursing and medical staff. After completing the checklist, it was filed with patients' medical record.

In this protocol implementation stage, the sector counted on the performance of a trained nurse, identified as "sepsis protocol manager", for four hours daily (during the day or night shifts). During this period, they worked exclusively to search for patients with suspected sepsis and supported their conduct in the initial treatment of cases, such as triggering the staff for exam collection, preparation and administration of antimicrobials, care hemodynamic monitoring and record.

\section{Population and sample; inclusion and exclusion criteria}

Convenience sampling consisted of patients over 12 years old admitted consecutively with sepsis or septic shock, or who evolved with these diagnoses during care at the emergency unit. Palliative care patients were excluded. This sample was classified according to pre-intervention and intervention and type of care provided by the health staff to septic patients.

The sample of patients in the intervention phase was divided into three categories, according to the type of care they received: 1) Patients assisted by a trained staff who used the checklist; 2) Patients assisted by a trained staff, without using the checklist; 3) Patients seen with support of a sepsis protocol manager (Figure 1).

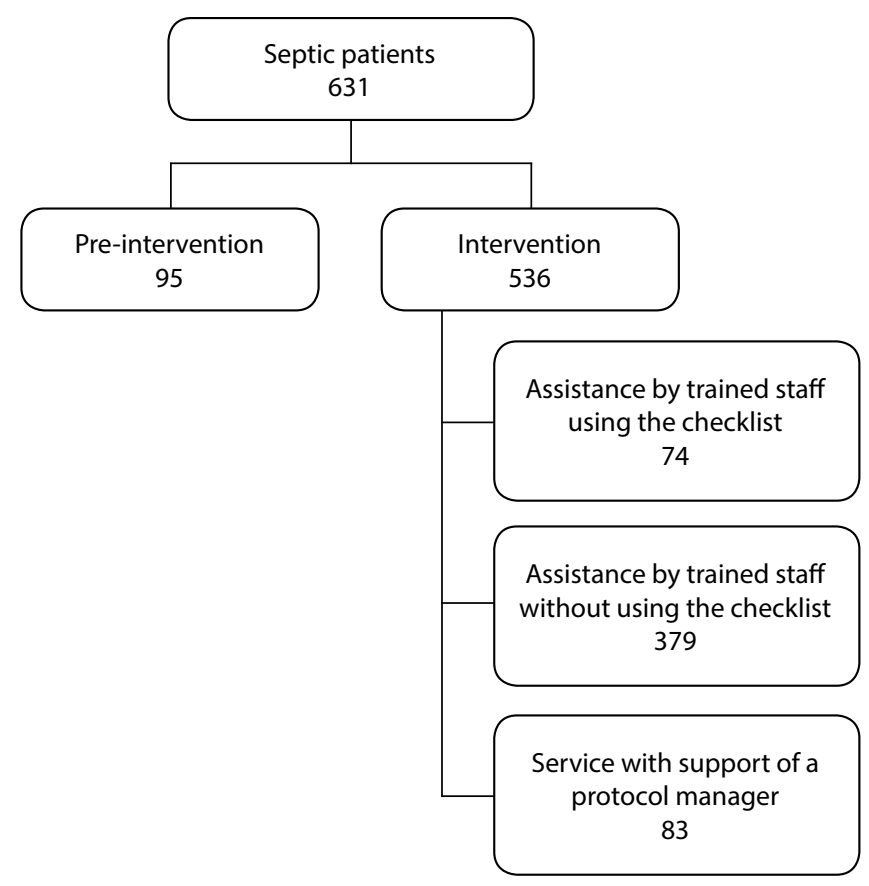

Figure 1 - Study sample distribution regarding protocol implementation and type of care provided to septic patients according to the sepsis managed care protocol, Londrina, Paraná, Brazil, 2013 to 2018
Type of care received by patients happened according to the medical and nursing staff convenience, who chose whether to use the checklist or not. Assistance with support of a protocol manager took place at times when this professional was part of the sector staff, and recorded his or her participation in a medical record. Type of service was recognized by the data collection staff by identifying checklist files and records of sepsis managers in medical records. The sample data were collected retrospectively from the medical records and printed from patients' checklist.

\section{Analysis of results and statistics}

Analysis of visits to septic patients included the following clinical, epidemiological and demographic variables: age (elderly $\geq 65$ years), sex, infectious focus, sepsis category (sepsis and septic shock), antimicrobial therapy, use of mechanical ventilation, hospitalization length, organ dysfunctions, clinical outcome and Sequential Organ Failure Assessment (SOFA) score, which ranges from 0 to 4 considering the clinical and laboratory parameters of cardiovascular, respiratory, neurological, renal, hematological, hepatic and metabolic functions. A score of 2 or more represents organ dysfunction.

Quality indicators of treatment for septic patients considered the latest SSC guidelines. Therapeutic conducts, called treatment packages, were considered adherent in the first hour ${ }^{(12)}$ and third hour $^{(8)}$ of sepsis recognition, with conducts collecting serum lactate, collecting blood culture, starting antimicrobial therapy, volume replacement of crystalloid $(30 \mathrm{~mL} / \mathrm{kg}$ ) in patients with hypotension or hyperlactatemia (lactate $\geq 4.4 \mathrm{mmol} / \mathrm{L}$ ) and use of vasopressors to maintain mean arterial pressure above $65 \mathrm{mmHg}$.

Checklist use and support of a sepsis protocol manager in patient care were considered to be independent variables of the study phases (pre-intervention and intervention). Sepsis treatment quality indicators, represented by adherence to lactate collection, blood culture, administration of antimicrobials, hemodynamic therapy, adherence to treatment packages performed within one or three hours from diagnosis and mortality were dependent variables.

Data were tabulated in Microsoft Office Excel 97 - 2013 and analyzed using the statistical program Epi Info ${ }^{\mathrm{TM}}$, version 7.2.2.6 (Centers for Disease Control and Prevention, Atlanta, USA). The results of continuous variables were described as mean, standard deviation (SD) or median and interquartile range (ITQ), depending on data distribution. Categorical variables were analyzed through the chi-square test. For all tests, $p$ value less than 0.05 was considered significant, and $95 \%$ confidence interval $(\mathrm{Cl})$ was calculated when necessary.

\section{RESULTS}

The study sample consisted of 631 septic patients seen in an emergency department, characterized in Table 1, 95 from preintervention and 536 from intervention phases of the managed sepsis protocol.

As for sample characterization, the median age was 68 years (ITQ: 13-98), showing a predominance of elders (54.67\%) and male. The most frequent infectious focus was pneumonia, followed by urinary tract infection. Regarding category, sepsis was more frequent than septic shock. 
Regarding organ dysfunctions due to sepsis, the mean SOFA score was 8.36 (SD 4.65) and median 8.0 (ITQ: 0-21). The median SOFA was equal (8.0) both in the pre-intervention stage as an intervention, showing similarity regarding the severity of samples. Serum lactate was measured in 557 patients, of whom the mean value was $2.93 \mathrm{mmol} / \mathrm{L}$ (SD 2.59); $50.27 \%$ (280) of patients presented hyperlactatemia; 371 (58.80\%) patients evolved to respiratory dysfunction and needed mechanical ventilation.

The most frequent dysfunction was arterial hypotension (63.87\%). Among the 403 hypotensive patients, 120 (29.78\%) received volume replacement according to the protocol recommendations; of these, $44(36.67 \%)$ had their blood pressure normalized; 76 (63.33\%) patients remained hypotensive, of which $73(96.05 \%)$ received vasopressors, while 3 (3.95\%) did not.

Table 1 - Characterization of septic patients ( $N=631)$, distributed in preintervention and intervention phases regarding clinical-demographic and epidemiological variables, Londrina, Paraná, Brazil, 2013-2018

\begin{tabular}{lccc}
\hline Variables & Total & $\begin{array}{c}\text { Pre-intervention } \\
\mathbf{9 5}(\mathbf{1 5 . 0 5})\end{array}$ & $\mathbf{5 3 6 ( 8 4 . 9 5 )}$ \\
\hline Sex & & & \\
$\quad$ Male & & & \\
$\quad$ Female & $354(56.10)$ & $52(54.74)$ & $302(56.34)$ \\
Infectious focus & $277(43.90)$ & $43(45.26)$ & $234(43.66)$ \\
$\quad$ Pneumonia & $443(70.20)$ & $77(81.05)$ & $366(68.28)$ \\
$\quad$ Urinary tract infection & $98(15.53)$ & $12(12.63)$ & $86(16.04)$ \\
$\quad$ Other infections & $82(13.00)$ & $6(6.32)$ & $76(14.18)$ \\
$\quad$ Focus not defined & $8(1.27)$ & 0 & $8(1.50)$ \\
Sepsis category & & & \\
$\quad$ Sepsis & $393(62.28)$ & $59(62.11)$ & $334(62.31)$ \\
$\quad$ Septic shock & $238(37.72)$ & $36(37.89)$ & $202(37.69)$ \\
Hospitalization length & & & \\
$\quad$ Up to 7 days & $181(28.68)$ & $20(21.05)$ & $161(30.04)$ \\
$\quad$ to 15 & $175(27.73)$ & $21(22.10)$ & $154(28.73)$ \\
$\quad$ From 16 to 30 & $148(23.45)$ & $30(31.58)$ & $118(22.01)$ \\
$\quad>30$ days & $127(20.14)$ & $24(26.26)$ & $103(19.22)$ \\
Outcome & & & \\
$\quad$ Discharge & $253(40.10)$ & $35(36.84)$ & $218(40.67)$ \\
$\quad$ Death & $378(59.90)$ & $60(63.16)$ & $318(59.33)$ \\
\hline
\end{tabular}

The time between sepsis clinical manifestation and recognition averaged 4.55 hours (SD 6.09) in the pre-intervention period and 3.50 hours (SD 4.73) in the intervention period $(p=0.057)$; $389(61.65 \%)$ patients were diagnosed within the first hour after organ dysfunction, of which 328 (84.32\%) were treated during the intervention period.

Concerning treatment of septic patients, protocol implementation, as well as checklist use and support of a sepsis protocol manager, showed a positive impact on treatment quality indicators.

Protocol implementation (Table 2) increased the chances of a patient receiving a package of measures by 14 times, and favored all treatment indicators, except adherence to hemodynamic treatment, which showed a reduction of $18.06 \%$ in the intervention phase. There was no significant reduction (3.83\%) in the frequency of mortality in the intervention phase.

Checklist use (Table 3 ) increased the chances of a patient receiving the package of measurements in 4 times in one hour; however, it did not show statistical significance in adherence to lactate collection within the third hour of diagnosis, nor did it contribute to blood culture collection, but significantly reduced (22.75\%) mortality.

Support of a sepsis protocol manager (Table 4) increased the chances of a patient receiving a package of measures by 8 times in one hour, but did not favor adherence to hemodynamic treatment. Mortality was reduced by $10.33 \%$.

There was a reduction of 6 days (from 18 to 12 days) in the median of hospitalization length of patients seen during protocol implementation ( $p<0.001$ ). There was no difference in hospitalization length between patients in the intervention phase, comparing those who were seen with a checklist or by a protocol manager.

\section{DISCUSSION}

The results of this study showed that implementing a protocol based on SSC recommendations, using strategies for checklist use and participation of a sepsis protocol nurse manager, resulted in a positive impact on sepsis treatment quality indicators, increasing the possibilities of a patient receive the recommended care.

Table 2 - Comparative analysis of septic patients $(\mathrm{N}=631)$ treated in pre- and post-intervention periods regarding treatment quality and mortality indicators, Londrina, Paraná, Brazil, 2013-2018

\begin{tabular}{|c|c|c|c|c|c|c|c|}
\hline Adherence to lactate collection & $\begin{array}{l}\text { Total } \\
\text { n (\%) }\end{array}$ & $\begin{array}{l}\text { Pre-intervention } \\
95(15.06 \%)\end{array}$ & $\begin{array}{l}\text { Intervention } \\
536(84.94 \%)\end{array}$ & Odds Ratio & \multicolumn{2}{|c|}{$\begin{array}{c}(95 \%) \\
\text { confidence interval }\end{array}$} & $p$ value \\
\hline $\begin{array}{l}1^{\text {st }} \text { hour } \\
3^{\text {rd }} \text { hour }\end{array}$ & $\begin{array}{l}291(52.24) \\
438(78.64)\end{array}$ & $\begin{array}{l}16(23.53) \\
35(51.47)\end{array}$ & $\begin{array}{l}275(56.24) \\
403(78.06)\end{array}$ & $\begin{array}{l}4.1764 \\
4.4183\end{array}$ & $\begin{array}{l}2.3194 \\
2.6019\end{array}$ & $\begin{array}{l}7.5201 \\
7.5026\end{array}$ & $\begin{array}{l}<0.001 \\
<0.001\end{array}$ \\
\hline $\begin{array}{l}\text { Adherence to blood culture collection } \\
1^{\text {st }} \text { hour } \\
3^{\text {rd }} \text { hour }\end{array}$ & $\begin{array}{l}297(55.00) \\
424(78.52)\end{array}$ & $\begin{array}{l}26(39.39) \\
38(57.58)\end{array}$ & $\begin{array}{l}271(57.17) \\
386(81.43)\end{array}$ & $\begin{array}{l}2.0538 \\
3.2321\end{array}$ & $\begin{array}{l}1.2135 \\
1.8830\end{array}$ & $\begin{array}{l}3.4761 \\
5.5478\end{array}$ & $\begin{array}{r}0.005 \\
<0.001\end{array}$ \\
\hline $\begin{array}{l}\text { Adherence to antimicrobial therapy } \\
1^{\text {st }} \text { hour } \\
3^{\text {rd }} \text { hour }\end{array}$ & $\begin{array}{l}209(42.22) \\
346(69.90)\end{array}$ & $\begin{array}{l}7(12.50) \\
22(39.29)\end{array}$ & $\begin{array}{l}202(46.01) \\
324(73.80)\end{array}$ & $\begin{array}{l}5.9662 \\
4.3542\end{array}$ & $\begin{array}{l}2.6438 \\
2.4453\end{array}$ & $\begin{array}{l}13.4639 \\
7.7530\end{array}$ & $\begin{array}{l}<0.001 \\
<0.001\end{array}$ \\
\hline Adherence to hemodynamic therapy & $333(73.51)$ & $69(88.46)$ & $264(70.40)$ & 0.3102 & 0.1496 & 0.6432 & $<0.001$ \\
\hline $\begin{array}{l}\text { Adherence to treatment packages } \\
1 \text { hour package } \\
\text { 3-hour package }\end{array}$ & $\begin{array}{l}71(11.25) \\
152(24.09)\end{array}$ & $\begin{array}{l}1(1.05) \\
6(6.32)\end{array}$ & $\begin{array}{l}70(13.06) \\
146(27.24)\end{array}$ & $\begin{array}{c}14.1202 \\
5.5530\end{array}$ & $\begin{array}{l}1.9372 \\
2.3775\end{array}$ & $\begin{array}{c}102.9204 \\
12.9698\end{array}$ & $\begin{array}{l}<0.001 \\
<0.001\end{array}$ \\
\hline Mortality & $378(59.90)$ & $60(63.16)$ & $318(59.33)$ & 0.8509 & 0.5420 & 1.3360 & 0.279 \\
\hline
\end{tabular}


Table 3 - Comparative analysis of septic patients treated with and without a checklist $(n=453)$ regarding the indicators of treatment quality and mortality, Londrina, Paraná, Brazil, 2013-2018

\begin{tabular}{|c|c|c|c|c|c|c|c|}
\hline \multirow{2}{*}{ Adherence to lactate collection } & \multirow[t]{2}{*}{$\begin{array}{l}\text { Total } \\
\text { n (\%) }\end{array}$} & \multirow[t]{2}{*}{$\begin{array}{c}\text { Without checklist } \\
379(70.71 \%)\end{array}$} & \multirow[t]{2}{*}{$\begin{array}{l}\text { With checklist } \\
74(29.29 \%)\end{array}$} & \multirow[t]{2}{*}{ Odds Ratio } & \multicolumn{2}{|c|}{$\begin{array}{l}(95 \%) \\
\text { confidence interval }\end{array}$} & \multirow[t]{2}{*}{$p$ value } \\
\hline & & & & & & & \\
\hline $1^{\text {st }}$ hour & 205(50.00) & 159(46.90) & $46(64.79)$ & 2.0830 & 1.2240 & 3.5448 & 0.0043 \\
\hline $3^{\text {rd }}$ hour & $327(79.76)$ & $266(78.47)$ & $61(85.92)$ & 1.6741 & 0.8172 & 3.4292 & 0.1014 \\
\hline \multicolumn{8}{|l|}{ Adherence to blood culture collection } \\
\hline $1^{\text {st }}$ hour & 204(51.91) & $162(50.63)$ & $42(57.53)$ & 1.3214 & 0.7909 & 2.2076 & 0.1746 \\
\hline $3^{\text {rd }}$ hour & $310(78.88)$ & $250(78.13)$ & $60(82.19)$ & 1.2923 & 0.6709 & 2.4893 & 0.2754 \\
\hline \multicolumn{8}{|l|}{ Adherence to antimicrobial therapy } \\
\hline $1^{\text {st }}$ hour & $150(40.98)$ & $111(37.00)$ & $39(59.09)$ & 2.4595 & 1.4278 & 4.2365 & $<0.001$ \\
\hline $3^{\text {rd }}$ hour & $259(70.77)$ & $196(65.33)$ & $63(95.45)$ & 11.1429 & 3.4158 & 36.3499 & $<0.001$ \\
\hline Adherence to hemodynamic therapy & $223(71.47)$ & $200(74.07)$ & $23(54.76)$ & 0.4237 & 0.2177 & 0.8245 & 0.0099 \\
\hline \multicolumn{8}{|l|}{ Adherence to treatment packages } \\
\hline 1 hour package & $36(7.95)$ & $21.54(5.54)$ & $15(20.27)$ & 4.3341 & 2.1148 & 8.8824 & $<0.001$ \\
\hline 3-hour package & $99(21.85)$ & $68(17.94)$ & $31(41.89)$ & 3.2972 & 1.9385 & 5.6081 & $<0.001$ \\
\hline Mortality & $276(60.93)$ & $245(64.64)$ & $31(41.89)$ & 033943 & 0.2374 & 0.6550 & $<0.001$ \\
\hline
\end{tabular}

Note: statistical test: Pearson's chi-square.

Table 4 - Comparative analysis of septic patients $(n=536)$ treated with and without support of a sepsis protocol manager regarding treatment quality and mortality indicators, Londrina, Paraná, Brazil, 2013-2018

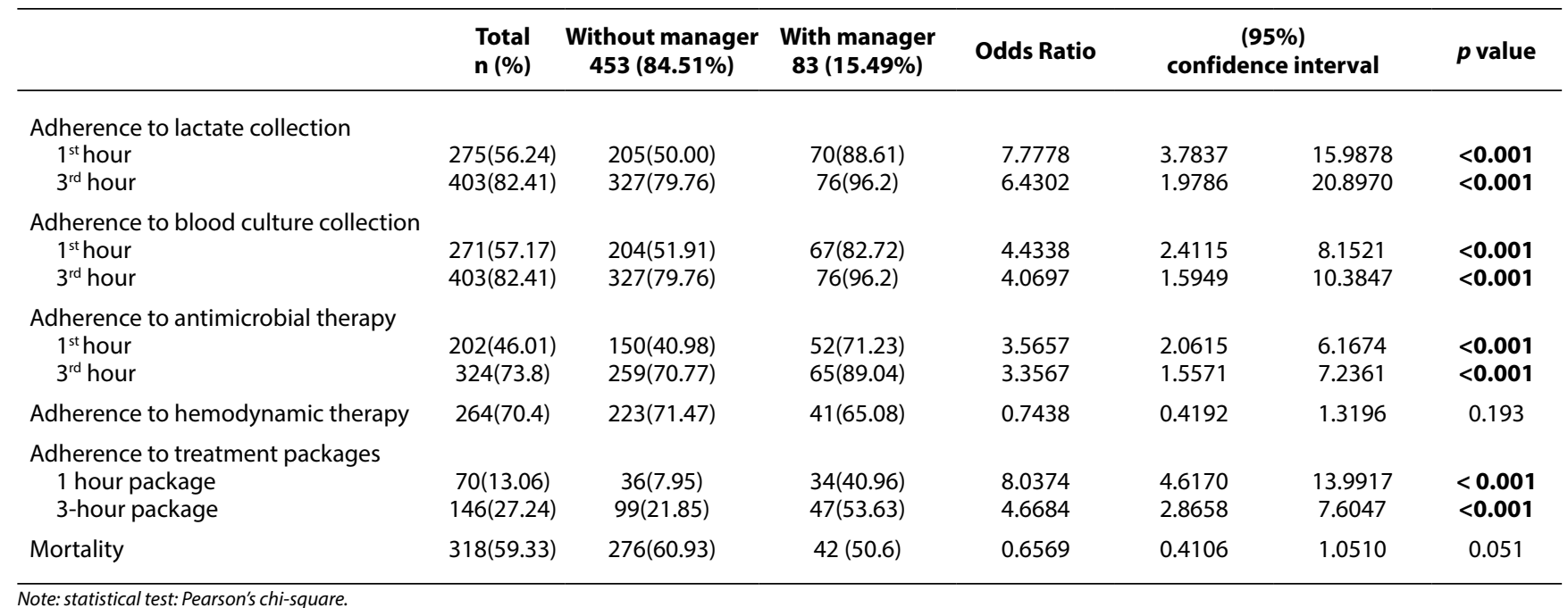

According to SSC guidelines, for treatment to be instituted in the recommended time, it is necessary that the diagnosis is early ${ }^{(8)}$. The present study showed that there was a tendency to reduce the time to detect sepsis with protocol implementation. This result is similar to that of a North American study that assessed the implementation of sepsis protocols, conducted by nurses in an emergency unit, where more than half of septic patients were diagnosed within the first hour from the dysfunction ${ }^{(11)}$.

According to SSC, serum lactate collection within the first hour of sepsis recognition is one of the quality indicators of managed sepsis protocol, being strongly recommended in suspected cases. Hyperlactatemia is an important indicator of organ dysfunction, which reflects cellular metabolism alteration due to tissue hypoperfusion, triggered by the systemic inflammatory respons $\mathrm{e}^{(7-8,12-13)}$. Corroborating this recommendation, adherence to lactate collection in the first hour was higher in the group whose care was directed by checklist use and the participation of a sepsis protocol manager.
Blood culture collection is a key moment for adequate targeting of sepsis antimicrobial therapy, and should preferably be performed before antimicrobial administration, in order to reduce the serum microbial load a few minutes after the first dose of the appropriate antimicrobial. However, the same recommendation prioritizes a rapid administration of antimicrobials if it is not logistically possible to obtain cultures promptly ${ }^{(8)}$. In this regard, the present study showed that implementing a protocol, using a checklist and a manager's participation in caring for septic patients significantly increased the chances of collecting blood culture in the first hours of sepsis recognition; however, it was unable to measure whether cultures were collected before or after infusion of antimicrobials.

Antimicrobial therapy should be prioritized in cases of sepsis, and its administration must be carried out in the first hour after the clinical condition recognition, considering that each hour of delay in infectious focus control is related to increased mortality ${ }^{(8)}$. Studies show that there is a great variability in time for administration of the first dose of the antimicrobial in cases of sepsis treated 
in emergency sectors ${ }^{(10,14)}$. Despite being a recommendation that does not imply an increase in costs, there are several barriers that lead to the delay of this medication, such as late recognition of sepsis, unavailability of these drugs at diagnosis site and workload of nursing professionals in charge of medication preparation and administration. For a health institution to achieve adherence to this indicator, great involvement of the entire health staff and a high degree of care organization is required. The present study showed that the strategies implemented by the managed protocol increased the chances of adhering to this treatment indicator.

As for hemodynamic therapy, which includes volume replacement and use of vasopressors ${ }^{(8,12)}$, a significant reduction in adherence was observed in the intervention period, except in care analysis with the presence of a sepsis manager. This fact can be justified by the manager's support in preparing and controlling crystalloid solution infusion during his or her presence in the sector.

The recent update of SSC recommends that therapeutic measures for sepsis be implemented in the first hour, considering as time zero the moment of sepsis recognition ${ }^{(12,15)}$. For some health services, reaching this time is a major challenge, especially considering emergency emergency services of public institutions, which face overcrowding of patients. In this study, there was a significant increase in adherence to treatment packages at one and three hours after managed sepsis protocol implementation. We believe that one of the factors that contributed to this improvement was the daily presence of a sepsis protocol manager in the sector supporting the staff in real time for the identification and treatment of septic patients.

A Brazilian study, carried out in the emergency department of the same hospital in the present study, showed a hospitalization length close to 30 days among septic patients and an impact on the increase in hospital costs ${ }^{(6)}$. The current study showed that managed sepsis protocol implementation reduced the median hospitalization length for septic patients from 18 to 12 days, and hospitalization for a period longer than 30 days went from $26.26 \%$ of the sample to $19.22 \%$.

Regarding mortality, studies indicate that implementing protocols based on SSC recommendations can reduce mortality. This fact is related to the improvement in the diagnosis process, making the implementation of the therapy recommended by SSC guidelines earlier ${ }^{(9-11)}$. This reduction is a consequence of early detection and institution of treatment, minimizing complications.

In the emergency department of the current study, checklist use and support of a sepsis protocol manager in patient care contributed to increase adherence to recommendations and patient survival, which increased from $36.84 \%$ at pre-intervention to $40.67 \%$ in at intervention. A study carried out in 118 Brazilian ICUs, which used a safety checklist for critically ill patients by the multidisciplinary staff, showed improvement in the adoption of the recommended measures and in the perception of safety by the multidisciplinary staff ${ }^{(16)}$.

Implementing institutional protocols and staff training directly impacts the survival of patients with sepsis as well as the conduction and optimization of the time of early diagnosis ${ }^{(9-10)}$. Among the strategies for implementing the protocol assessed in the current study, using a checklist showed a significant reduction in mortality, showing that it is an important tool in health services that has difficulties in allocating exclusive human resources for clinical protocol management.

\section{Study limitations}

As limitations in the study, we point to absence of analyzes related to reassessment of fluid status and tissue perfusion, new measurement of lactate for patients with initial hyperlactatemia, as well as information on blood culture collection, preceding antimicrobial therapy. Such measures are recommended by SSC; however, they have not been assessed in the current study due to the absence of notes on these parameters in patients' records.

\section{Contributions to nursing}

The study presents analysis of sepsis treatment indicators associated with the strategies adopted for implementing a managed protocol for caring for septic patients, such as checklist use by health professionals and support of nurses in the management of actions to recognize and treat an important infectious complication.

Such results can support the implementation of managed protocols in health services, with emphasis on the role of nurses in the modality of protocol manager.

\section{CONCLUSIONS}

We evidenced that implementing the managed sepsis protocol led to improvements in quality indicators of treatment of this infectious disease. The findings indicate that the practical strategies for conducting the protocol by trained professionals, a checklist use and support of protocol nurse managers add to quality of health care and patient safety.

\section{REFERENCES}

1. Singer M, Deutschman CS, Seymour CW, Shankar-Hari M, Annane D, Bauer M, et al.The third international consensus definitions for sepsis and septic shock (sepsis-3). JAMA. 2016;315(8):801-10. https://doi.org/10.1001/jama.2016.0287

2. Fleischmann C, Scherag A, Adhikari NK, Hartog CS, Tsaganos T, Schlattmann P, et al. Assessment of global incidence and mortality of hospitaltreated sepsis. Current estimates and limitations. Am J Respir Crit Care Med. 2016;193(3):259-72. https://doi.org/10.1164/rccm.201504-07810C

3. Rudd K, Johnson SC, Agesa, KM, Shackelford KA, Tsoi D, et al. Global, regional, and national sepsis incidence and mortality, 1990-2017: analysis for the Global Burden of Disease Study. Lancet. 2020;395(10219):200-11. https://doi.org/10.1016/S0140-6736(19)32989-7

4. Machado FR, Cavalcanti AB, Bozza FA, Ferreira EM, Angotti Carrara FS, Souza JL, et al. The epidemiology of sepsis in Brazilian intensive care units (the Sepsis PREvalence Assessment Database, SPREAD):an observational study. Lancet Infect Dis. 2017;17(11):1180-9. https://doi. org/10.1016/S1473-3099(17)30322-5 
5. Torio CM, Moore BJ. National inpatient hospital costs: the most expensive conditions by payer, 2013. HCUP statistical brief no. 204 [Internet]. Rockville, MD: Agency for Healthcare Research and Quality. 2016[cited 2019 Oct 10]. Available from: http://www.hcup-us.ahrq.gov/reports/ statbriefs/sb204-Most-Expensive-Hospital-Conditions.pdfpdf icon

6. Barreto FMC, Gomes Dellaroza MS, Kerbauy G, Grion CMC. Sepsis in a university hospital: a prospective study for the cost analysis of patients' hospitalization. Rev Esc Enferm USP. 2016;50(2):302-8. https://doi.org/10.1590/S0080-623420160000200017

7. Dellinger RP, Levy MM, Rhodes A, Annane D, Gerlach H, Opal SM, et al. Surviving sepsis campaign: international guidelines for management of severe sepsis and septic shock: 2012. Crit Care Med. 2013;41(2):580-637. https://doi.org/10.1097/CCM.0b013e31827e83af

8. Rhodes A, Evans LE, Alhazzani W, Levy MM, Antonelli M, Ferrer R, et al. Surviving sepsis campaign: international guidelines for management of sepsis and septic shock: 2016. Crit Care Med. 2017;45(3):486-552. https://doi.org/10.1097/CCM.0000000000002255

9. Kaukonen KM, Bailey M, Suzuki S, Pilcher D, Bellomo R. Mortality related to severe sepsis and septic shock among critically III patients in Australia and New Zealand, 2000-2012. JAMA. 2014;311(13):1308-16. https://doi.org/10.1001/jama.2014.2637

10. Husabø G, Nilsen RM, Flaatten H, Solligård E, Frich JC. Early diagnosis of sepsis in emergency departments, time to treatment, and association with mortality: An observational study. PLoS One. 2020;15(1):e0227652. https://doi.org/10.1371/journal.pone.0227652

11. ILAS. Instituto Latino Americano de Sepse. Roteiro de implementação de protocolo assistencial gerenciado de sepse: programa de melhoria de qualidade [Internet]. 2019[cited 2019 Oct 10]. Available from: https://ilas.org.br/assets/arquivos/ferramentas/roteiro-de-implementacao.pdf

12. Levy MM, Evans LE, Rhodes A. The Surviving sepsis campaign bundle: 2018 Update. Crit Care Med. 2018;46(6):997-1000. https://doi. org/10.1097/CCM.0000000000003119

13. Bakker J. Lactate is THE target for early resuscitation in sepsis. Rev Bras Ter Intensiva. 2017;29(2):124-13. https://doi.org/10.5935/0103-507x.20170021

14. Hayden GE, Tuuri RE, Scott R, Losek JD, Blackshaw AM, Schoenling AJ, et al. Triage sepsis alert and sepsis protocol lower times to fluids and antibiotics in the ED. Am J Emerg Med. 2016;34(1):1-9. https://doi.org/10.1016/j.ajem.2015.08.039

15. Seymour CW, Liu VX, Iwashyna TJ, Brunkhorst FM, Rea TD, Scherag A, et al. Assessment of clinical criteria for sepsis for the third international consensus definitions for sepsis and septic shock (sepsis-3). JAMA. 2016;315(8):762-74. https://doi.org/10.1001/jama.2016.0288

16. Cavalcanti AB, Bozza FA, Machado F R, Salluh JIF, Campagnicci VP, Vendramin P, et al. Effect of a quality improvement intervention with daily round checklists, goal setting, and clinician prompting on mortality of critically IIl patients: a randomized clinical trial. JAMA. 2016;315(14):1480-90. https://doi.org/10.1001/jama.2016.3463 